\title{
O homem, a sociedade e o Estado: um diálogo em prol da civilização
}

\author{
Dayse Juliani ${ }^{1}$
}

\begin{abstract}
Resumo
A união dos homens em sociedade e a conseqüente formação dos Estados estão intimamente ligadas à própria natureza humana. Da tendência natural de viver em meio de seus semelhantes, da necessidade de cooperação entre eles, a fim de que se satisfaçam suas necessidades e sejam capazes de sobreviver, observa-se uma constante evolução das formas associativas humanas, desde as mais primitivas sociedades até o paradigma estatal adotado por nós nos dias atuais, o Estado Democrático de Direito, como superação das formas estatais anteriores, o qual considera o homem na sua complexidade, dotado de dignidade, considerado no aspecto de pessoa humana.
\end{abstract}

Palavras-Chave: Sociabilidade humana; Sociedade; Civilização; Estado; Processo civilizatório.

\section{Introdução}

Conhecer a natureza humana, suas tendências associativas, é imperativo necessário a fim de que possamos compreender o convívio do homem com os seus semelhantes na formação das sociedades e sua constante evolução, mormente no que tange à formação dos Estados.

Trata-se de um trabalho jusfilosófico na busca de maior compreensão a respeito do homem e sua colaboração na formação e evolução das mais antigas sociedades até 0 paradigma estatal adotado pela nossa Constituição Federal de 1988, o Estado Democrático de Direito, um longo processo que ainda se encontra em desenvolvimento.

O homem, ser complexo e instigante, possuidor de múltiplas dimensões, supera os demais seres vivos em diversos aspectos. Vai além, é capaz de superar a si próprio - quando da busca por novos horizontes, novos conhecimentos - transpor barreiras, como os seus mais íntimos medos, para alcançar o fim almejado, e então, iniciar nova busca, que vá ainda além daquela conquistada, em um contínuo processo.

Entre as tantas dimensões humanas, as de maior relevância para o nosso estudo, são a sociabilidade e a politicidade presentes na natureza humana, responsáveis pela

\footnotetext{
${ }^{1}$ Acadêmica do 50 ano de Direito matutino da Universidade Estadual de Londrina.
} 
aproximação do homem a seus semelhantes, a fim de criarem juntos, associações estáveis e se relacionarem como membros do mesmo grupo social.

Este aspecto da natureza humana vem sendo bastante discutido desde os filósofos da antiguidade, prevalecendo duas principais correntes doutrinárias, a dos naturalistas, a exemplo de Aristóteles e Platão, e a dos contratualistas, como Hobbes e Rousseau. Os primeiros vêem a necessidade de associação como própria da natureza humana, intrínseca ao homem, enquanto os segundos acreditam na formação das sociedades como resultado de um pacto, um contrato social feito entre os homens, a fim de satisfazerem suas necessidades, as quais, sozinhos não conseguiriam.

Destas associações nascem as primeiras sociedades, que com o passar do tempo, necessitam de um poder que seja capaz de conduzi-las e dirimir os conflitos que passaram a existir com o crescimento do corpo social, por divergências de opiniões e outros motivos, formando dentro das sociedades, grupos menores, secundários, ligados por vínculos de afinidade. Surgem, assim, as chamadas sociedades políticas, caracterizadas por uma autoridade superior, dotada de poder político, que fixam regras de convivência para seus membros, visando a harmonia entre seus membros e as sociedades secundárias existentes.

Das sociedades políticas se formam os Estados, dotados de características próprias. Ocorre, porém, que o Estado nem sempre foi como conhecemos hoje, e por isso, a fim de se compreender sua evolução até os dias atuais - a forma de Estado que conhecemos e em que vivemos, o Estado Democrático de Direito - serão abordados neste trabalho, as várias formas de Estado.

Temos o Estado Democrático de Direito como superação de todos os paradigmas estatais anteriores, preocupado com o indivíduo, o homem no sentido de pessoa humana, dotado de dignidade, além de buscar o bem comum, a paz social para seu povo, como um todo.

\section{Considerações sobre o homem}

Para situarmos o homem na sociedade, é necessário tentarmos compreender a natureza humana.

O homem diferencia-se dos demais seres por ser dotado de razão, a qual lhe dá a consciência de sua grandeza, e, ao mesmo tempo, das limitações de sua existência. 
Erich Fromm (1968, p. 44), ao analisar o homem, apontou dicotomias existenciais e históricas de sua natureza. Definiu a primeira, como sendo aquelas enraizadas na própria existência do homem, aquelas que o homem não pode anular, mas a que pode reagir de diferentes maneiras, relativas a seu caráter e a sua cultura. As dicotomias históricas, por sua vez, são as tantas contradições da vida individual e social, porém estas, suscetíveis de solução, ainda que em um momento posterior.

0 fato de não haver um padrão a ser seguido na vivência do homem, é o que 0 maravilha frente a tantas possibilidades e, também, 0 amedronta diante de tantos caminhos a escolher, por saber que muitos de seus atos trarão conseqüências futuras, próximas ou distantes daquele momento de decisão, a si próprio e aos demais que façam parte de seu convívio.

A sociabilidade e politicidade humanas

Dentre as tantas possibilidades da natureza humana, das suas múltiplas dimensões, tem maior relevância para o presente estudo, a dimensão social e política do homem (Homo socialis).

Antônio Bento Betioli $(2002$, p. 17) traz em sua obra de propedêutica jurídica, que em qualquer lugar ou época que se observe o homem, ele sempre se encontra em convívio de outros, desde pequenos grupos sociais, como a família, a clã, a tribo, até grupos maiores, como a aldeia, a cidade, e o Estado, sendo, portanto, a sociabilidade e a politicidade, as duas dimensões fundamentais apresentadas pelo homem.

A primeira corresponde à propensão do homem para viver junto dos seus semelhantes e comunicar-se com eles, torná-los participantes das mesmas experiências e a segunda refere-se ao conjunto de relações que o indivíduo mantém com os demais, enquanto membro de um grupo social. (M ONDIN, 2005, p. 159).

Verificamos o estudo desse impulso associativo da raça humana em diversos dos mais ilustres filósofos, com diferentes interpretações.

Platão vê o homem como essencialmente alma, que atinge sua perfeição e realiza sua felicidade na contemplação das Idéias, que povoam um mundo, denominado por ele, metaforicamente, de lugar celeste (topos uranos). Nesse sentido, não precisa, o homem, de ninguém. Acontece que, por uma grande culpa, as almas perderam sua condição original e 
caíram na Terra, onde foram condenadas a assumir um corpo e purificar-se, através de suas necessidades corpóreas que podem ser satisfeitas somente com a ajuda dos outros. A sociabilidade é, assim, conseqüência da corporeidade e dura enquanto as almas estiverem ligadas ao corpo. (BETIOLI, 2005, p. 18).

Para Aristóteles (1978, p. 73), diferentemente de Platão, é propriedade essencial do homem o fato deste ser, por natureza, civilizado, sendo este, constituído de corpo e alma, o que o leva, necessariamente, a ligar-se aos vínculos sociais, já que sozinho, é incapaz de satisfazer suas necessidades e realizar suas aspirações. Em decorrência disto, como demonstra em sua obra A Política, o filósofo considera aquele que vive à margem da sociedade, como um Deus ou um animal, ou seja, um ser superior ou inferior ao homem, pois "o homem é, por natureza, um animal político.

Também São Tomás De Aquino (1995, p. 127), considera o homem um animal sociável e político que vive em sociedade por natural necessidade.

Referente a esta "natural necessidade" de viver em sociedade, São Tomás de Aquino compara o homem aos animais irracionais e encontra justificativas para tal tendência, nas diferenças analisadas, como por exemplo, o discernimento nato dos animais do que lhes é útil ou nocivo, ou ainda o preparo dado pela natureza aos outros animais, que não o homem, como a defesa de dentes, garras, vestimentas de pêlos, velocidade, dentre outras. 0 homem, desprovido destes presentes da natureza, foi dotado de razão, a qual lhe permite conseguir, por meio de suas próprias mãos, todas essas coisas, insuficiente, porém, a um só homem. (AQUINO, 1995, p. 127).

Thomas Hobbes, a exemplo dos filósofos contratualistas, nega o impulso associativo natural do homem. 0 "estado de natureza" do homem, ou seja, o modo de ser que o caracterizaria antes de seu ingresso no "estado social", é de egoísmo.

Hobbes (1997, p. 13) afirma que todos os homens são, por natureza, iguais, dotados com a mesma força e as mesmas aptidões intelectuais, o que torna o recurso à violência generalizado, no sentido de elaboração de novos métodos de destruição do próximo. Como conseqüência disso seria um permanente estado de guerra nas comunidades primitivas, a "guerra de todos contra todos" ("bellum omnium contra omnes"). "O homem é o lobo do próprio homem" ("homo homini lupus”) é uma das frases mais famosas do filósofo inglês. 
A associação do ser humano se dá, portanto, pelo instinto de conservação, pois a vida de cada um estaria sob constante ameaça, se todos agissem conforme suas próprias vontades de exercer o poder sobre todas as coisas. Para a obtenção da paz, os homens estabeleceram contratos entre si, onde transferem o poder de governar a si próprios a um terceiro, o Estado, para que este governe a todos.

Jean-Jacques Rousseau, outro filósofo contratualista, vê de maneira oposta à de Hobbes, o estado natural do homem, sendo para ele, o homem bom e livre.

Para Rousseau (1978, p. XVI), este estado natural termina com o surgimento da propriedade privada, que força os homens a viverem em sociedade, sob o poder de uma Autoridade, cujas leis, ao invés de manter a justiça e a ordem, deram mais forças aos ricos, que acabaram com o estado natural, sujeitando os demais à miséria e ao trabalho servil.

A realização do eu comum e da vontade geral implicam necessariamente um contrato social.

O Estado, segundo Rousseau (1978, p. XX) deveria ser guiado pela "vontade geral" ("volonté générale"), atendendo aos interesses comuns a todos, e não pela de vontade de um ou de alguns. Esta seria a única forma de o homem não ser corrompido pela sociedade nem tornar-se infeliz ao fazer parte dela.

Da exposição dos vários estudos expostos, é possível concluir que a sociedade é fruto tanto da natureza do homem, quanto da sua vontade e consciência na formação desta.

Dalmo De Abreu Dallari (2003, p. 18) afirma que a predominância atual é a aceitação da sociedade como resultado de uma natural necessidade humana, sem a exclusão da participação da consciência e vontade do homem.

\section{Da sociedade}

Conforme o exposto, há aqueles que defendem a idéia de origem da sociedade, como sendo natural, decorrente da própria natureza humana, e aqueles que crêem que a sociedade se dá simplesmente através de um acordo de vontades.

Com o passar do tempo, embora todas apresentem como elementos a finalidade ou valor social, as manifestações de conjunto ordenadas e o poder social, diferentes tipos de sociedade foram se formando, pois os homens que buscam os mesmos objetivos tendem a associar-se para alcançá-los com maior facilidade (DALLARI, 2003, p. 46). 
Diante disso tem-se a necessidade de um poder social superior que concilie esses diferentes grupos, em função de um fim geral comum. Este fim geral comum coloca, de um lado, as instituições governamentais e, de outro, as demais espécies de agregados, ou seja, denominam-se sociedades de fins particulares, as que têm finalidade definida, voluntariamente escolhida por seus membros, sendo que suas atividades visam ao objetivo que inspirou sua criação; e as sociedades de fins gerais, são aquelas cujo objetivo é genérico, indefinido, a fim de criar as condições necessárias para que todos que dela participem, sejam indivíduos ou outras sociedades menores que nela se integram, consigam atingir seus fins particulares. "A participação nestas sociedades quase sempre independe de um ato de vontade." (DALLARI, 2203, p.47).

As chamadas sociedades políticas são as sociedades de fins gerais, pois não se restringem a setores limitados da atividade humana, mas buscam integrar todas as atividades sociais existentes em seu âmbito.

\section{Civilização e barbárie}

A civilização e a barbárie devem ser entendidas por meio do estudo de seus diferentes sentidos.

Os sentidos a serem analisados são três. Civilização, no primeiro deles, é sinônimo de civilidade; no segundo sentido, é a parte espiritual da cultura; e, no terceiro, é a humanidade do sentido moral. (WOLF, 2003, p. 23).

Os bárbaros, por sua vez, são, no primeiro sentido, pertencentes a um estágio arcaico de socialização; no segundo, a um estagio arcaico de cultura; e, num terceiro momento, de maior gravidade que os demais, são pertencentes a um estágio pré-humano: "é o homem que permaneceu em um estágio selvagem, que se tornou, ou tornou a ser, desumano". (WOLF, 2003, p. 24).

A respeito do exposto, tem-se que no primeiro sentido da barbárie, a civilização tem o papel de desenvolver um processo, por meio do qual os povos evoluem socialmente, no sentido de se livrarem dos costumes rudimentares das sociedades fechadas, para se "civilizarem", o que pressupõe que passem a pertencem a uma sociedade maior, aberta e complexa. Teoricamente, trata-se de um processo progressivo, por meio do qual há um abrandamento dos costumes grosseiros, e um aprendizado de respeito aos modos, ao 
pudor, etc., tanto no cumprimento das funções naturais, como por exemplo, se alimentar, defecar, cuspir, quanto nas relações sociais, como a polidez, se comportar durante a refeição, e como dirigir-se ao outro. (WOLF, 2003, p. 21).

Bárbaros, portanto, são aqueles que ignoram as boas maneiras e se comportam como brutos, se incluem num estágio inferior da evolução política.

Civilização, no segundo sentido, não diz respeito à cultura como um todo, mas a parte da cultura humana relacionada às ciências, às letras e às artes, a parte especulativa, contemplativa e espiritual da vida, o saber puro, a filosofia, a poesia, a música erudita, entre outros, em detrimento das técnicas e ofícios, do prático e utilitário.

Neste sentido, os bárbaros são anteriores a própria cultura humana, pois só reconhecem o valor no útil, no prático, na satisfação das necessidades vitais ou dos prazeres grosseiros e, portanto, não reconhecem o valor do saber ou da beleza pura, ou não compreendem seu sentido. Tal sentido remonta às grandes invasões bárbaras ocorridas na Europa, que se iniciaram no século III. (WOLF, 2003, p. 22).

0 terceiro sentido designa o lado humano da civilização, principalmente nas relações com outros homens ou outras sociedades. Há desta forma, cooperação, assistência, compaixão, conciliação e pacificação das relações, em oposição à natureza primitiva, violenta, arcaica, onde impera a luta impiedosa pela sobrevivência. São bárbaros, por sua vez, aqueles "dotados de uma brutalidade feroz, cega e selvagem, sem motivo razoável, e sobretudo, sem limite racional."

A civilidade liga-se ao conceito de "humanidade", à medida que passa a considerar as individualidades de cada um.

Os três sentidos analisados apresentam traços comuns, já que os três casos nos mostram uma separação entre o que há de humano, de progresso social, e o primitivo, 0 inculto, o bruto, o selvagem. Visto por esse ângulo, a oposição civilização/barbárie se aproxima da oposição cultura/natureza.

Importante se faz mencionar que não existe uma idéia única de barbárie que reúna os três sentidos identificados.

0 que, visto do lado de fora de uma sociedade, parece bárbaro, parecerá humano e civilizado quando visto do lado de dentro daquela. Essa inversão dos pontos de vista é o suficiente para que se invertam os julgamentos. Trata-se da estratégia do relativismo. 
Temos, pois, que bárbara é toda cultura, que não possua estrutura que lhe permita admitir ou reconhecer outra cultura, ou seja, a existência de outra forma de humanidade. São, da mesma forma, bárbaros, os atos, costumes ou práticas que têm como finalidade a negação de uma forma específica da existência humana. (WOLF, 2003, p. 41)

Diferentemente, civilizações são "os momentos históricos, os espaços geográficos, as áreas culturais que permitem a coexistência, tanto de fato, como de direito, de vários povos, sociedades ou culturas". (WOLF, 2003, p. 41). Diante disso, dizemos que uma cultura é civilizada quando, independentemente do seu nível de desenvolvimento técnico, por exemplo, ela recepciona a diversidade de crenças ou práticas, desde que estas não sejam bárbaras, evidentemente.

\section{Do estado}

O Estado se forma a partir de sociedades organizadas politicamente, com autoridade superior e que fixa regras de convivência para seus membros (DALLARI, 2003, p. 52).

Tem-se conhecimento do Estado como ordem política da Sociedade desde a antiguidade. Ocorre, todavia, que nem sempre teve essa mesma denominação, nem tampouco encobriu a mesma realidade.

Excetuando algumas variações, os autores costumam classificar a evolução do Estado, com uma seqüência cronológica que compreende o Estado Antigo, Estado Grego, Estado Romano, Estado M edieval e Estado Moderno.

No Estado Antigo não se distingue o pensamento político da religião, da moral, da filosofia e das doutrinas econômicas. Há, porém, duas marcas fundamentais do Estado neste período: a natureza unitária e a religiosidade, sendo que a primeira diz respeito ao Estado aparecer como uma unidade geral, sem divisões interiores, a qual persiste durante toda a evolução política da Antiguidade. A religiosidade, por sua vez, se faz tão presente, que 0 Estado desse período recebe a denominação, por alguns autores, de Estado Teocrático. Foi esta, a influência predominante, sendo que essa teocracia, de maneira geral, significa que há uma estreita ligação entre os Estado e a divindade, afirmando-se, inclusive, a autoridade dos governantes e as normas de comportamento, como expressões da vontade divina (DALLARI, 2003, p. 62). 
Com relação ao Estado Grego, não se tem conhecimento de um Estado único, porém pode-se falar de forma genérica sobre ele, devido a certas características fundamentais, comuns a todos os Estados que englobam a população helênica, sendo a principal delas, a cidade-Estado, ou seja, a polis, como a sociedade política de maior expressão, cujo ideal visado era a auto-suficiência (DALLARI, 2003, p. 63).

o Estado Romano teve início com um pequeno agrupamento humano, experimentou diversas formas de governo, expandiu seu domínio por uma vasta expansão do mundo, atingindo os mais diferentes povos, chegando a constituir um império mundial (NASCIM ENTO, 2006, p. 25), multiétnico, e devido a isso era obrigado a criar condições harmoniosas de convivência entre homens de diferentes procedências.

Temos, portanto, como herança da cultura romana, o direito privado e 0 humanismo. Através do direito privado, surge a noção de pessoa humana individual, ou seja, cada homem possui uma natureza que lhe é própria.

O Estado M edieval, por sua vez, foi um período bastante instável e heterogêneo, 0 que torna difícil elencar suas características. No entanto, é possível estabelecer a configuração e os princípios informativos das sociedades políticas, que superaram a rigidez da organização romana, revelando novas aspirações, que culminaram no Estado M oderno, a citar o cristianismo, as invasões dos bárbaros e o feudalismo como os principais elementos presentes na sociedade política medieval. (DALLARI, 2003, p. 66).

Enquanto a Igreja tentava reunir os Estados num poderoso Império, os povos do norte da África e do Oriente Médio sentiam-se encorajados a fazer incursões à Europa, percebendo a pouca resistência. Em algumas regiões, os cristãos, divididos entre si, chegam a celebrar alianças com chefes bárbaros, havendo, em alguns, casos, relações amistosas para fins econômicos entre estes.

O feudalismo, outro elemento de grande influência para a concretização do Estado Medieval, deve ser compreendido, levando-se em conta as invasões e as guerras que ocorriam internamente, o que dificultava o desenvolvimento do comércio. Disso decorre uma grande valorização da posse da terra, onde todos, independentemente de classe social, tirarão sua subsistência. Desenvolve-se, portanto, um sistema administrativo e uma organização militar estreitamente ligados à situação patrimonial. (DALLARI, 2003, p. 69). 
Quanto ao Estado Moderno, há uma diversidade de opiniões, tanto a respeito da identificação de seus elementos, quanto do número. Dallari (2003, p. 71) nos apresenta quatro elementos característicos: a soberania, o território, o povo e a finalidade.

De forma simples, Darcy Azambuja (1979, p. 62) define soberania como o poder do Estado, supremo sobre os indivíduos e as sociedades de indivíduos que formam sua população, além de sua independência diante dos demais Estados.

A formação de seu conceito, no entanto, é trabalho complexo, por variar no tempo e no espaço, o que deu margem a tantas discussões doutrinárias.

O território é componente necessário do Estado. Não existe Estado sem território, embora a perda temporária deste não desnature o Estado, que continua a existir, enquanto haja a possibilidade de se reintegrar ao território, com os demais elementos. 0 mesmo acontece com as perdas parciais de território (DAШALI, 2003, p. 90). É através deste que a delimitação da ação soberana do Estado fica estabelecida.

O povo deve ser compreendido como o conjunto dos indivíduos que se unem para constituir o Estado, estabelecendo com este um vínculo jurídico de caráter permanente, participando, assim, da vontade do Estado e do exercício do poder soberano. Estes adquirem a condição de cidadãos, podendo conceituar o povo como o conjunto de cidadãos do Estado. (DALLARI, 2003, p. 100).

\section{Do estado moderno}

O Estado M oderno abrange uma longa história de mudanças e transformações nas formas de instituição estatal, assim como na própria sociedade.

Sua fase mais antiga é caracterizada pelo Estado absolutista, seguida então, pelo Estado liberal, Estado social, e Estado Democrático de Direito.

O Estado absolutista é caracterizado pela concentração de todo o poder nas mãos de uma pessoa, geralmente o monarca.

Essa forma de Estado teve início na Idade Média, porém tomou forma na Idade Moderna. Têm-se como teóricos de destaque, acerca do absolutismo, Maquiavel, Jean Bodin, Bossuet e Hobbes. 
Thomas Hobbes defendia a idéia de um Estado absolutista, pois segundo ele, esta seria a única forma de os homens poderem viver em paz. Sua principal obra foi o livro Leviatã, onde expressa a idéia de um Estado forte, dominante e poderoso.

Em virtude da natureza egoísta do homem, todos os membros da sociedade deveriam transferir o poder de governarem a si próprios, ao Estado, através de um contrato social. Tal poder deve ser exercido de maneira despótica, pois, segundo Hobbes, essa seria a única maneira de se manter a paz e a ordem social. (HOBBES, 1997, p. 13).

Maquiavel aborda em 0 Príncipe, escrito em 1515, a arte de se conquistar e manter o poder. Não teve, ele, inclusive, problemas em sugerir aos governantes, práticas de fraudes, perfídias e crueldades para isto (LIM A, 2000, p. 169). A busca por um Estado forte justifica qualquer ato.

Com relação a isso, Cláudio Emanuel Correa Lima (2000, p. 188) entende que 0 Príncipe não tem cunho moralista nem imoral, é, pois um trabalho "técnico", no sentido de indicar o que pode ou não ser útil. Maquiavel, através desta obra, faz advertências e presta informações necessárias aos mandantes de novos principados, a fim de protegerem seus governos dos perigos que os cercavam.

A finalidade de um governante é manter a unidade da paz, e por isto, Tomás De Aquino (1995, p. 55) defende que o poder político seja exercido por um único governante, pois, segundo este filósofo, o "governo de um só" é mais útil para a conservação da unidade da multidão dissensiosa e, sendo de maior utilidade, terá maior eficácia na obtenção de seu escopo. Fala-se em maior utilidade devido às dificuldade que podem ser encontradas nos "governos de muitos", por divergências entre os governantes, por exemplo. Ressalta também a importância da escolha do governante, para que tal governo não se torne tirania, considerado por ele o pior governo.

Ocorre que as revoluções burguesas ocorridas na Europa transformaram a sociedade feudal, em busca de uma nova forma de Estado, que não o absolutista, em ruptura da hierarquia por laços sanguíneos e dos privilégios. Surge assim, o Estado Liberal.

O Estado Liberal teve como seu principal marco a Revolução Francesa, iniciada em 1789, em oposição à organização política anterior, o qual não permitia a participação daqueles, no poder, que não fizessem parte da nobreza, realeza ou clero. 
Surge o Estado Social, como fruto da superação do antigo liberalismo e com o escopo de promover o bem estar social, o qual estende sua influência a quase todos os setores que até então, em grande parte, pertenciam à esfera individual (BONAVIDES, 2007, p. 186).

Importante mencionar que o Estado Social é uma fase do Estado Moderno, o qual surgiu como conseqüência das revoltas e revoluções ocorridas pelos operários excluídos, de certa maneira, da ordem social, e que não se pode confundir com o Welfare State, o qual decorreu do término da Segunda Guerra Mundial, pela necessidade de restauração da Europa.

O Estado Social, assim como o Estado Liberal, não foi capaz de implementar e concretizar as múltiplas dimensões dos direitos fundamentais em seu conjunto. Conforme faz men ção Sérgio Alves Gomes (2006, p. 284), o Estado Social, tendencioso a transformar-se em Estado "socialista", autoritário, foi capaz de ver apenas, os interesses de um grupo, a "classe trabalhadora", mas não os de cada indivíduo, enquanto pessoa humana. A falha do Estado Liberal, por sua vez, neste sentido, foi sua passividade diante das desigualdades entre as classes sociais, caracterizadas pelos operários, desprovidos de qualquer bem que não fosse sua força de trabalho, e os proprietários dos meios de produção.

Surge então, a necessidade de um novo paradigma de Estado, que supere todos os anteriores e seja capaz de suprir suas faltas: 0 Estado Democrático de Direito.

O Estado Democrático de Direito é um paradigma de Estado comprometido com os valores da democracia, ou seja, o poder político se origina da vontade popular e encontra seu propósito e limite no princípio da dignidade humana (GOMES, 2006, p. 289).

Na reunião dos princípios do Estado Democrático e de Estado de Direito, o Estado Democrático de Direito não o faz como mera união formal dos respectivos elementos, pois "traz um novo conceito que os supera, na medida em que incorpora um componente revolucionário de transformação do status quo". (SILVA, 2004, p. 112).

O Estado Democrático de Direito preocupa-se com o homem, no sentido de pessoa humana, tendo, desta forma, como fundamento maior o princípio da dignidade humana.

Os direitos fundamentais são as diretrizes do Estado Democrático de Direito. Sendo que seus valores, como a vida, a liberdade, a igualdade, a segurança, a propriedade, a educação, a saúde... propiciam a vivência do homem de forma digna. 
A fim de garantir as liberdades individuais dos cidadãos, a burguesia formulou os princípios filosóficos de sua revolta social e os doutrinou como ideais comuns a todos os integrantes da sociedade. Ocorre, porém, que ao tomar o controle político, esta sustenta apenas de maneira formal a universalidade daqueles princípios, sendo que, de fato, conservam princípios constitutivos de uma ideologia de classes (BONAVIDES, 2007, p. 42).

0 liberalismo não pôde resolver o problema essencial de ordem econômica das camadas proletárias da sociedade, não dava nenhuma solução às contradições sociais, mormente daqueles que se encontravam à margem da vida, desapossados de quase todos os bens. A liberdade política como liberdade restrita era inoperante e, por isso o Estado Liberal entrou irremediavelmente em crise (BONAVIDES, 2007, p. 188).

A atitude passiva do Estado Liberal diante das reais desigualdades sociais existentes provocou lutas da população pelo reconhecimento dos direitos sociais, com base na idéia de igualdade.

\section{Conclusão}

Do exposto, conclui-se que o processo civilizatório compreende uma série de fatos e fatores, tais como a natureza humana, a cooperação entre os homens e a busca pelo bem comum do corpo social.

A própria natureza do homem o fez como um ser sociável e político, sendo que por esta razão ele não é capaz, em normais condições, de viver isoladamente. 0 homem necessita da convivência com seus semelhantes. Dos estudos e teorias apresentadas a este aspecto humano, conclui-se que embora prevaleça a corrente naturalista quanto à tendência do homem em viver em sociedade, esta não deve negar a contribuição da corrente contratualista, tendo-se, portanto, uma união das duas correntes filosóficas. Neste sentido, observa-se que o homem tende naturalmente à aproximação de outros da sua espécie, para com estes conviver. Para tanto, estabelece também, de forma simbólica, um acordo, um contrato social, a fim de que a paz social exista em tal sociedade, na busca do bem e da realização de todos os seus membros.

Da simples associação humana, das mais primitivas sociedades, formadas pela união dos homens, pelo trabalho conjunto de seus membros, surge a necessidade de se delegar o poder do todo a alguém que seja capaz de governá-los, pois, devido ao 
crescimento dessas sociedades, ao aumento da população, subgrupos se formam dentro dessa sociedade, formados por interesses comuns daqueles que a eles pertencem. A sociedade maior, desta forma, torna-se uma sociedade política.

Da evolução das sociedades políticas nasce o Estado, dotado de um poder político soberano, capaz de dirimir os conflitos existentes, governar a todos que nele se encontrem, na busca do bem comum.

São várias as formas de Estado encontradas, estando este em constante evolução. Da análise dos paradigmas anteriores, chega-se a constatação de que o paradigma de Estado atual, o Estado Democrático de Direito é a superação de todos eles, principalmente por considerar o homem como pessoa humana, dotado de dignidade.

Este paradigma surge em respeito aos direitos da sociedade como um todo e não em defesa dos direitos de determinada classe ou de alguns direitos específicos, olvidando-se dos demais, como fizeram os paradigmas anteriores.

Nele estão presentes os valores da democracia, fruto do diálogo e do mútuo respeito, através da qual o povo participa da vida pública, por meio da democracia representativa. 0 Estado Democrático de Direito resulta, portanto, da escolha do povo, e tem como elementos o homem, a sociedade e o Estado, os quais contribuem para a sua realização.

Cabe à hermenêutica constitucional a interpretação dos princípios que fundamentam este paradigma, de modo que sejam concretizados em profundidade, já que o Estado Democrático de Direito apresenta-se como um processo em construção.

A luta pela concretização histórica deste paradigma parece estar ainda no começo.

\section{Referências}

AQUINO, S. Tomás de. Escritos político de Santo Tomás de Aquino. Tradução de Francisco Benjamin de Souza Neto - Petrópolis, RJ: Vozes, 1995. - (Clássicos do pensamento político).

ARISTÓTELES. Tópicos; Dos argumentos sofísticos. Seleção de textos de José Américo Motta Pessanha; traduções de Leonel Vallandro e Gerd Bornheim da versão inglesa de W. A. Pickard. São paulo: Abril Cultural, 1978. (Coleção Os Pensadores).

AZAM BUJA. Darcy. Introdução à ciência política. 3. ed. Porto Alegre: Ed. Globo, 1979. BETIOLI, Antonio Bento. Introdução ao Direito. Lições de Propedêutica Jurídica. 8. ed. São Paulo, SP: Editora Letras \& Letras. 
BONAVIDES, Paulo. Do Estado Liberal ao Estado social.8. ed. Ed. Malheiros.

DALLARI, Dalmo de Abreu. Elementos de teoria geral de Estado. 24. ed. São Paulo: Saraiva, 2003.

FROM M , Erich. Análise do Homem. Tradução de Octavio Alves Velho. 6. ed. Rio de Janeiro: Zahar Editores, 1968.

GOM ES, Sérgio Alves. Possibilidades da hermenêutica constitucional na construção do Estado Democrático de Direito. 2006. Tese (Doutorado em Filosofia do Direito e do Estado) Pontifícia Universidade Católica de São Paulo, São Paulo, 2006.

HOBBES, Thomas. Leviatã ou Matéria, forma e poder de um estado eclesiástico e civil. Tradução de João Paulo Monteiro e M aria Beatriz Nizza da Silva. São Paulo: Abril Cultural, 1997. (Coleção Os Pensadores).

LIM A, Cláudio Emanuel Correa. 0 simbolismo em Maquiavel: ensaio em duas partes. Fortaleza: EUFC, 2000.

M ONDIN, Battista. 0 homem: quem é ele?: elementos de antropologia filosófica. Tradução de R. Leal Ferreira e M. A. S. Ferrari. 12. ed. São Paulo: Paulus, 2005.

NASCIM ENTO, Walter Vieira do. Lições de História do direito. 15. ed. ver. e aum. Rio de Janeiro: Ed. Forense, 2006.

NOVAES, Adauto (Org.). Civilização e barbárie. São Paulo: Companhia das Letras, 2004.

SILVA, José Afonso da. Curso de Direito Constitucional Positivo. São Paulo: Ed. Malheiros, 2005. 